\title{
Benefits of distributed energy storage working in parallel to distributed energy resources
}

\author{
A. Goikoetxea ${ }^{1}$, J. A. Barrena ${ }^{1}$, M. A. Rodríguez ${ }^{2}$, G. Abad ${ }^{1}$ \\ ${ }^{1}$ Faculty of Engineering, University of Mondragon, Loramendi 4, 20500 Mondragon, Spain, e-mail: \\ agoikoetxea@eps.mondragon.edu, jabarrena@eps.mondragon.edu \\ ${ }^{2}$ Ingeteam Transmission \& Distribution, S.A., Protección y control de redes eléctricas - C/ Usausuaga, 7 Pol. \\ Artunduaga48970 Basauri (Bizkaia) - Spain, e-mail: miguelangel.rodriguez@ingeteam.com
}

\begin{abstract}
In the context of new policies promoting the use of distributed energy resources (DER) the number of distributed generation (DG) units connected to the medium voltage (MV) and low voltage (LV) distribution grids has largely increased. Distribution companies offer different prices to DG owners depending on the signal quality and time-slot, because the price of sale of generated energy is influenced by the curve of the demand. The use of energy storage systems can help for a larger integration of DG controlling the power flow in the point of common coupling (PCC). From the economical point of view, the possibility to store the electricity when the price is low to sell when it is high makes energy storage an interesting investment for DG owners. In this article is discussed the use of distributed energy storage (DES), paying attention on the control requirements for a larger DG penetration and the economical benefits. The aim of the article is to develop a control strategy to increase economical profits assuring supply quality, for energy storage systems working in parallel to DG units.
\end{abstract}

\section{Key words:}

Distributed Generation, Small wind farm, Statcom, Battery Storage, electricity price, active management

\section{Introduction}

The electrical grid is one of the largest infrastructures ever built. This infrastructure has been built regarding a generation model where large centrals should provide the electricity to supply all the customers. In this grid topology, the power produced by these centrals is transmitted in $\mathrm{HV}$ to consumption points, changing there to MV for its distribution and finally is transformed to LV for its consumption. Due to environmental concerns and the variable price of fossil fuels, renewable energy sources are getting more importance for power generation. Even if large wind farms or hydroelectric centrals are connected to the transmission grid, a large amount of renewable energy is connected to the distribution network. These generation units can be defined as distributed generation (DG). The increasing penetration of DG is already changing the network topology [1]. Due to the policies that aim the increase of renewable energies, subsidizing the electricity produced by renewable sources and the liberalization of electricity markets are promoting this change of the network topology.

In this context many customers are becoming electricity suppliers. Distribution grid operators are forced to buy this electricity but the price of this electricity can be variable depending on the power quality and time-slot. In Spain the R.D.661/2007 gives the chance to DG owners to sell the electrical power in the free market complemented by a bonus or in a fixed price. This rule defines also the complements for the control of reactive power, depending on the power factor or the needs of distribution system operators. Using energy storage with a STATCOM connected in parallel to DG units it is an interesting technology in order to get as much benefits as possible, on the one hand it gives the possibility to store the electricity when the price is low to sell it when the price is high, on the other hand the STATCOM gives the possibility for reactive power compensation.

Furthermore, the use of power converters gives different possibilities, such as active and reactive power compensation of loads, network voltage control and mitigation of power system disturbances [2]. The use of batteries for the active management of distribution grids is discussed in [3], showing the possibility of developing a storage system suitable for improving the quality of supply on a grid and how a droop control of voltage and frequency enables the island operation.

This article focuses on the possible benefits of a Statcom with energy storage systems working in parallel to DG, from the point of view of DG owners. In this way, there will be discussed the most convenient management strategies in order to obtain economical profits for the DG owner. Therefore, the management strategy to sell as much power as possible when the price of the electricity is high in the market is going to be developed, controlling the reactive power to get as high complement as possible.

\section{Spanish electricity market}

Spain has a liberalized electricity market and is within the Iberian market. The price of the electricity depends on the offer of qualified suppliers and the demand of the 
qualified customers. There is an intermediate company (OMEL) for the economical management of the electricity market that assures the correct balance of the offer demand and the free competition. The electricity production market is divided in 4 processes, the diary market process where a first price is fixed depending on the offer and demand of each day, the solution of technical restrictions process, interdiary market process and the ancillary services and deviation management process. In this way a first price for the next day $\mathrm{kWh}$ is fixed for every, although the final price is fixed monthly after analyzing these four processes. For the wind farms there are two choices to sell electricity: sell it in a fixed price or sell it the free market complemented by a bonus. The bonus for the free market establishes a minimum and maximum price for the kWh of wind energy[4].

\section{Battery storage technologies}

Traditionally lead acid batteries have been used for electricity storage. The low cost and the maturity of this technology makes it still an interesting option for electricity storage. Even so the waste of these batteries is very toxic and this made interesting the development of other technologies. The REDOX flow batteries and the NaS batteries are the most mature technologies; many installations of these technologies there have been implemented during the last years. The storage cost is higher than lead acid batteries, but for discharge times of three hours the cost is the similar for REDOX and is not so high for NaS, but the cycle life is longer with these technologies, compared to lead acid batteries [5].

\section{Scenario for the study}

In order to analyze the economical benefits provided by a STATCOM with energy storage for the owners of DG installations it has been chosen the scenario developed in [6].

The scenario proposed is composed by a wind farm connected to the MV distribution network, working in parallel to a battery connected to the PCC by a Statcom..

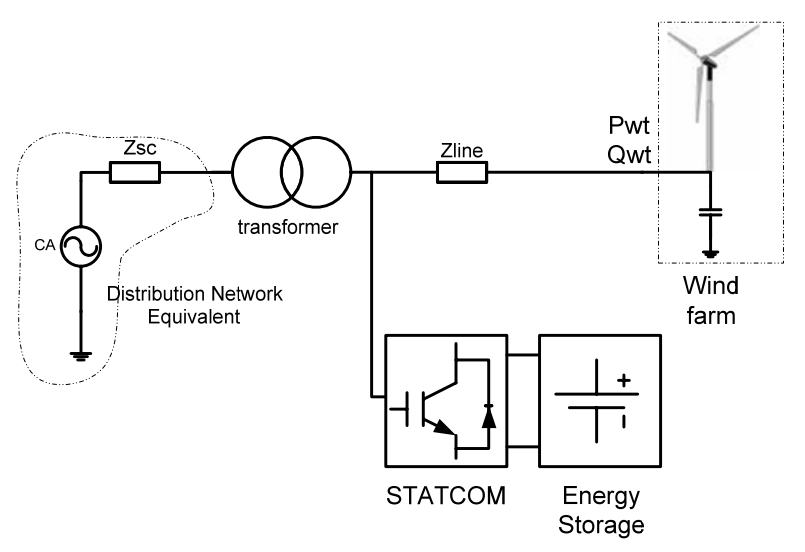

Figure 1: Scenario proposed for the study

\section{System modeling}

\section{A. Distribution grid}

The distribution network equivalent grid will be modeled in a first stage as an ideal voltage source with a short- circuit impedance with an adequate $\mathrm{X} / \mathrm{R}$ ratio. In this case the short circuit impedance is defined around the $10 \%$ of the nominal power of the wind farm, in order to simulate a weak network.

The $\mathrm{X} / \mathrm{R}$ ratio in distribution grids is around 10 .

\section{B. Wind turbine}

The fixed speed turbine model is composed of five cascaded elements:

- Wind profile, aerodynamic system and mechanical system.

- Asynchronous generator.

C. Statcom

The Statcom is composed of a three phases voltage source inverter connected to the grid by means of an inductive filter. In order to reduce the simulating time the modulator and the switches will be modeled as voltage controlled sources.

\section{Storage system}

The storage system is composed by the battery and the DC/DC converter. The converter is modeled by its medium model and the battery by means of an electrical model taking into account the battery lifetime and the voltage-current characteristics.

\section{Control strategies}

The control strategies are divided in two levels of control hierarchy:

\section{E. Converter control}

The converter control is responsible for active and reactive power exchange by the grid inverter control and the current control of battery. Among all the control strategies proposed for the voltage source inverter, for this study a vector control has been selected. In this case, it will receive as references, the active and reactive power supplied by the inverter. The bus voltage will be controlled by means of the control of the battery current, so a bus voltage regulator will provide a battery current reference. The crowbar control will act as a security system.

\section{F. Grid control}

The grid control consists on defining the active and reactive power references for the inverter. Depending on the price of the electrical energy and the prediction of wind power generation it will be interesting to absorb or supply power from the battery regarding to maintain the state of charge of the battery within safety limits, the active power reference for the battery will be defined taking into account the following variables. The price of wind power in the free market varies drastically depending on the time slot and it is directly related to the power consumption [7]. The control algorithm consists on storing energy during valley and plain time slots to supply the full power during peak time slot when the price should be normally the highest, as an exception during other time slots if the price of the electricity in the market is so high the battery would supply full power as 
well. The reactive power reference will be defined in order to control the power factor in the PCC, to get as much bonus as possible. In Spain the appendix $\mathrm{V}$ of R.D.661/2007 defines the reactive power bonus complement for DG owners.

\begin{tabular}{|c|c|c|c|c|}
\hline \multirow{2}{*}{$\begin{array}{c}\text { Power Factor } \begin{array}{c}\text { type } \\
\text { type }\end{array} \\
\text { Power Factor }\end{array}$} & \multicolumn{3}{|c|}{ Bonus \% } \\
\cline { 2 - 5 } & $\mathrm{PF}<0,95$ & -4 & -4 & 8 \\
\hline \multirow{5}{*}{ Inductive } & $0,96>\mathrm{PF}>0,95$ & -3 & 0 & 6 \\
\cline { 2 - 5 } & $0,97>\mathrm{PF}>0,96$ & -2 & 0 & 4 \\
\cline { 2 - 5 } & $0,98>\mathrm{PF}>0,97$ & -1 & 0 & 2 \\
\cline { 2 - 5 } & $1,00>\mathrm{PF}>0,98$ & 0 & 2 & 0 \\
\hline \multirow{5}{*}{ Capacitive } & 1,00 & 0 & 4 & 0 \\
\hline & $1,00>\mathrm{PF}>0,98$ & 0 & 2 & 0 \\
\cline { 2 - 5 } & $0,98>\mathrm{PF}>0,97$ & 2 & 0 & -1 \\
\cline { 2 - 5 } & $0,97>\mathrm{PF}>0,96$ & 4 & 0 & -2 \\
\cline { 2 - 5 } & $0,96>\mathrm{PF}>0,95$ & 6 & 0 & -3 \\
\cline { 2 - 5 } & $\mathrm{PF}<0,95$ & 8 & -4 & -4 \\
\hline
\end{tabular}

Table 1: bonus complement for reactive power, defined in R.D.661/2007

\section{Simulations}

The aim of the simulations is to show the benefits of an energy storage system for DG owners, following the previously mentioned control strategy. In this way, there will be calculated the economical profit of using a battery in parallel to a wind farm. Different simulations were made in order to analyze different opportunities for a $5 \mathrm{MW}$ wind farm; these results can be extrapolated to larger installations.

In a first step there were calculated the benefits of a wind farm selling the electricity in the free market with bonus and selling it to a fixed price. Afterwards there has been simulated the scenario of a Battery Energy Storage System (BESS) working in parallel to a wind farm. This system was analyzed for different storage capacities and different power conversion systems. Using the approximated costs of different BESS technologies [8] and the yearly benefits of the use of each battery in parallel to a wind farm, there is calculated the amortization time of the investment. The yearly benefits are considered the difference between the systems with the battery and the benefits of the wind farm itself without electricity storage. In these benefits are considered the sale of electricity and the bonus for reactive power control.

\section{A. Simulation data}

For the simulations was chosen the wind speed data, measured in a wind farm located on Oiz Mountain, Bizkaia, this data is available in [9]. Ten minutes mean wind speed it has been used.

The hourly price of the electricity in Spain is given in [4]. The sale of wind energy in Spain is complemented by a bonus that establishes a minimum and maximum price, this price is settled in $7,1275 \mathrm{c} € / \mathrm{kW}$ as minimum and $8,4944 \mathrm{c} € / \mathrm{kW}$ as maximum. With these data it has been simulated the previously defined system.

For the estimation of the investment on the BESS there have been chosen the following approximated costs from $[5,8]$ including the the battery and the power conversion system: for lead-acid batteries $260 € / \mathrm{kWh}$ and $325 € / \mathrm{kW}$, for $\mathrm{NaS}$ batteries $270 € / \mathrm{kWh}$ and $350 € / \mathrm{kW}$, for flow batteries $220 € / \mathrm{kWh}$ and $330 € / \mathrm{kW}$. The investment for an on-shore wind farm is normally between 1000 and $1500 €$ per $\mathrm{kW}$.

\section{B. Simulation results}

A Backward-Forward sweep Power Flow algorithm developed in [10] was used as a function to simulate the system in Matlab/Simulink. Table 2: Results of simulations shows the results of the simulations depending on the Power and the Energy available for each battery, the amortization time is calculated for three different types of batteries, based on the lowest prices available for each kind of battery.

Furthermore it has been calculated the amortization time if the wind power would not get any bonus, for the best case of the table. The results were improved notably and the amortization time was reduced to 50 years.

In the following figures there are different graphs of the simulations, where there are shown the wind speed, the power balance between the win farm and the battery, the energy stored in the battery and the price of the electricity during a certain period of time. These simulations were done for an 8MWxh battery with a nominal power of $2 \mathrm{MW}$. In the graph of electricity price there are the price of electricity in the free market and the price wind power electricity.

\begin{tabular}{|c|c|c|c|c|c|c|c|c|}
\cline { 4 - 9 } \multicolumn{4}{c|}{} & \multicolumn{2}{c|}{ Lead acid } & \multicolumn{2}{c|}{ NaS } & \multicolumn{3}{c|}{ Flow batteries } \\
\hline Power (MW) & Energy (MWxh) & Profits (€/year) & Investment (€) & Amort. (years) & Investment (€) & Amort. (years) & Investment ( () & Amort. (years) \\
\hline 5 & 40 & 52858,79 & 11931685,25 & 226 & 12672541,52 & 240 & 10391484,05 & 197 \\
\hline 10 & 40 & 83959,89 & 13569367,54 & 162 & 14427201,12 & 172 & 12048662,55 & 144 \\
\hline 4 & 32 & 43870,39 & 9545348,20 & 218 & 10138033,22 & 231 & 8313187,24 & 189 \\
\hline 8 & 32 & 50430,70 & 10855494,03 & 215 & 11541760,89 & 229 & 9638930,04 & 191 \\
\hline 3 & 24 & 34112,72 & 7159011,15 & 210 & 7603524,91 & 223 & 6234890,43 & 183 \\
\hline 6 & 24 & 45498,45 & 8141620,52 & 179 & 8656320,67 & 190 & 7229197,53 & 159 \\
\hline 2 & 16 & 19816,38 & 4772674,10 & 241 & 5069016,61 & 256 & 4156593,62 & 210 \\
\hline 4 & 16 & 37981,47 & 5427747,01 & 143 & 5770880,45 & 152 & 4819465,02 & 127 \\
\hline 1 & 8 & 11352,58 & 2386337,05 & 210 & 2534508,30 & 223 & 2078296,81 & 183 \\
\hline 2 & 8 & 20004,82 & 2713873,51 & 136 & 2885440,22 & 144 & 2409732,51 & 120 \\
\hline
\end{tabular}

Table 2: Results of simulations 

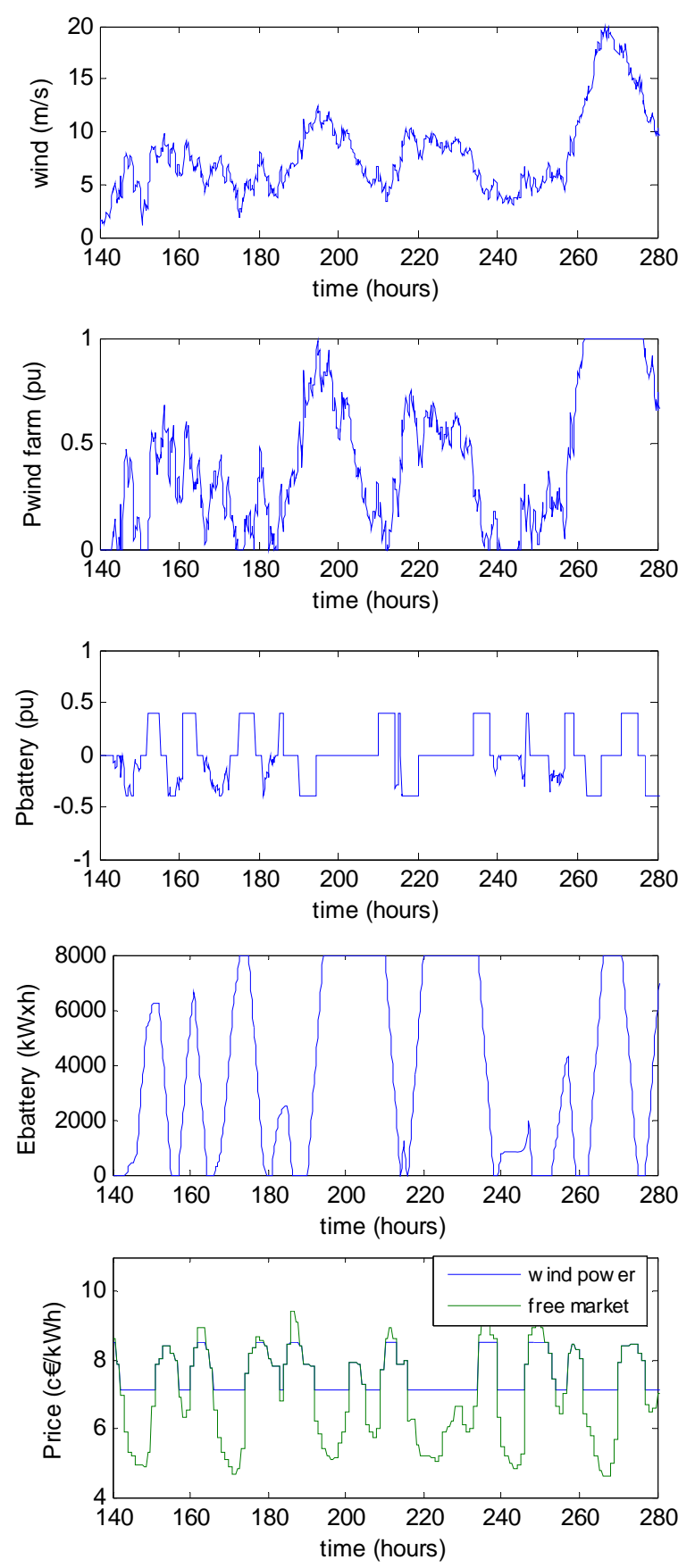

Figure 2: Temporal simulation (6 days)

\section{Conclusions}

Regarding the aim of Spain and EU to increase the penetration of wind power to a $20 \%$ of the total electricity production in 2020 and due to the variability of wind power production, the problematic of the grid stability will come up as one of the main problems for the further increase of renewable energy production. In this context the use of energy storage in parallel to wind farms are a very interesting alternative to make from the wind power a controllable electricity source. In fact there will be necessary to use electricity storage systems to control power balance in areas with high penetration of wind power. The use of a battery gives the chance to store the electricity production peaks, to supply the stored energy when there is not wind power available or when the power consumption is very high and there is the need of extra power source. In this way the use of BESS would avoid the collapse of the network.

The simulations presented in this paper have clearly shown that the connection of a battery working in parallel to a wind farm helps the network absorbing the excess power produced by the wind farm during consumption valleys, releasing this power during consumption peaks. This fact also represents benefits for the DG owners because the energy is stored when the prices are low and sold at higher prices. But the actual remuneration system reduces drastically the capability of a BESS to get benefits in the free market, because the larger difference between cheapest prices and most expensive prices for $\mathrm{kWh}$ is reduced to $1,4 \mathrm{c} € / \mathrm{kWh}$.

Looking at the results of the simulations a first conclusion is obvious, since the shortest amortization time is 120 years; it is not profitable to install a battery in parallel to a wind farm with the actual remuneration system. In this situation the investment of a BESS would be interesting only when the storage is necessary, like in islanded grids with a high penetration of renewable energies.

Since the need of energy storage seems to be necessary in a future electrical grid with a high penetration of renewable energies, it will be necessary to change the policy and give an incentive to DG owners in order to promote the installation of energy storage systems.

\section{References}

[1] T. Ackerman, G. Andersson, and L. Söder, "Distributed generation: a definition," Electric Power Systems Research-Elsevier, vol. 57, pp. pp. 195-204(10), 20 April 2001 2001.

[2] A. Arulampalam, J. B. Ekanayake, and N. Jenkins, "Application study of a STATCOM with energy storage," IEE Proceedings Gener. Transm. Distrib., vol. 150, 2003.

[3] S. Barsali, A. d. Donato, R. Giglioli, L. Guidi, E. Pasca, and S. Scalari, "Storage systems for the transition towards active and smart distribution systems," in ICREPQ Santander, 2008.

[4] OMEL, "www.omel.es," Operador del Mercado Eléctrico de Energía- Polo Español S.A., 2008.

[5] A. Oudalov, D. Chartouni, C. Ohler, and G. Linhofer, "Value Analysis of Battery Energy Storage Applications in Power Systems," in Power Systems Conference and Exposition, 2006. 
[6] A. Goikoetxea, "Design of control strategies to improve grid integration in fixed speed wind energy systems with battery storage," in ICREPQ 08 Santander, 2008.

[7] O. A. Pérez-Aradros, J. A. Domínguez, I. A. Aguarta, and L. Correas, "Determinación de la estrategia de producción de hidrógeno en un parque eólico real," in III congreso nacional de pilas de combustible Zaragoza, Spain, 2008.

[8] D. Rastler, "New Demand for Energy Storage," Electric Perspectives, vol. 33, 2008.

[9] www.euskalmet.euskadi.net: Meteorologia eta Klimatologia Zuzendaritza Eusko Jaurlaritza Gobierno Vasco, 2005.

[10] A. Milo, A. Martínez, M. Rodríguez, and A. Goikoetxea, "Dynamic power flow tool development for low voltage networks analysis with high penetration level of distributed generation," in ICREPQ 08 Santander, 2008. 